\title{
Insights into the emission reductions of multiple unintentional persistent organic pollutants from industrial activities
}

\author{
Guorui Liu ${ }^{a}$, Minghui Zhenga,*, Xiaoxu Jianga, Rong Jin ${ }^{a}$, Yuyang Zhao a, Jiayu Zhan ${ }^{\mathrm{b}}$ \\ a State Key Laboratory of Environmental Chemistry and Ecotoxicology, Research Center for Eco-Environmental Sciences, Chinese Academy of Sciences, P.O. \\ Box 2871, Beijing 100085, China \\ ${ }^{\mathrm{b}}$ State Key Laboratory of Solid Waste Reuse for Building Materials, Beijing Building Materials Academy of Sciences Research, Beijing 100041, China
}

\section{H I G H L I G H T S}

- Synergetic emission reduction of unintentional POPs was proposed.

- A comprehensive toxic evaluation system is needed for POP emission reduction.

- Identification of indicators for total emissions of multiple POPs is proposed.

- Preparation of inhibitor for synergistically blocking POP formation was suggested.

\section{A R T I C L E I N F O}

\section{Article history:}

Received 26 January 2015

Received in revised form 23 July 2015

Accepted 3 August 2015

Available online 18 September 2015

Handling editor: H. Fiedler

Keywords:

Persistent organic pollutant

Multi-pollutant control

Sustainable industrial development

Toxic emission evaluation

Quantitative correlation

Cost-benefit analysis

\section{G R A P H I C A L A B S T R A C T}

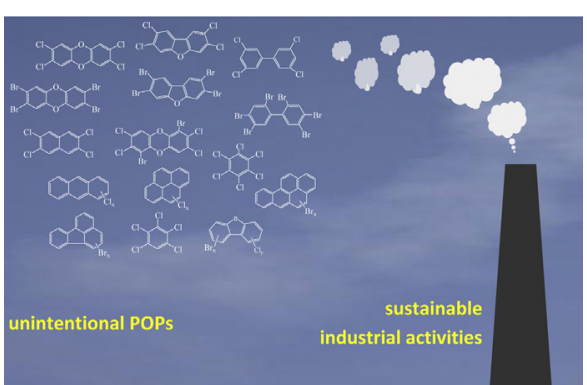

\section{A B S T R A C T}

Industrial activities result in unintentional production of multiple types of persistent organic pollutants (POPs) at various concentrations. Because of the potential adverse effect of these POPs on the environment, biota and human health, methods for controlling emission of POPs are required. Development and application of techniques for controlling emissions of POPs can be a technical and economic burden for the industry involved. Therefore, from the point of view of cost-benefit analysis, reducing emissions of multiple pollutants at the same time is optimal for sustainable industrial development. Although techniques have been developed for reducing the emissions of individual POPs, such as dioxins, further work is required on multi-POP control emissions from industrial activities. This paper discusses three important aspects that need to be taken to achieve multi-POP control. These aspects include the establishment of a comprehensive system for evaluating the risk from emissions of multiple POPs, determination of indicators for total emissions of multiple POPs, and the preparation and application of functional materials to inhibit formation of multiple POPs. These discussion might be helpful for the future research on the multi-POP control in industry.

(C) 2015 Elsevier Ltd. All rights reserved.

\section{Introduction}

Industrial activities contribute largely to the economy in many countries. For example, in China, coke production in 2007 was

\footnotetext{
* Corresponding author.

E-mail address: zhengmh@rcees.ac.cn (M. Zheng).
}

about $60 \%$ of global production, and iron smelting in 2008 was about 30\% of global production (Liu et al., 2009; Lv et al., 2011). Persistent organic pollutants (POPs) can be unintentionally formed during these industrial activities, and their emission has potential adverse effects on the environment, biota and human health. POPs are toxic, bio-accumulate, and are resistant to degradation and persist in the environment (Wagrowski and Hites, 2000; Van den Berg et al., 2006; Horii et al., 2009). The POPs that 
have been identified in industrial emissions include polychlorinated dibenzo-p-dioxins (PCDDs) and dibenzofurans (PCDFs), polychlorinated biphenyls (PCBs), polychlorinated naphthalenes (PCNs), hexachlorobenzene $(\mathrm{HxCBz})$, pentachlorobenzene (PeCBz), polybrominated dibenzo-p-dioxins (PBDDs) and dibenzofurans (PBDFs), mixed polybrominated/chlorinated dibenzo- $p$-dioxins and dibenzofurans (PXDD/Fs), polybrominated biphenyls (PBBs), chlorinated polycyclic aromatic hydrocarbons (Cl-PAHs), and brominated PAHs (Br-PAHs) (Buser et al., 1991; Akimoto et al., 1997; Yang et al., 1998; Zhang et al., 2005; Horii et al., 2008; Liu et al., 2009, 2010; Du et al., 2010). The structures of several of these POPs are shown in Fig. 1.

The unintentional emission of POPs from metallurgical industrial activities and waste incineration poses a potential risk to human health (Shih et al., 2006, 2008; Ma et al., 2009). We previously found that levels of dioxins and dioxin-like compounds in secondary nonferrous smelting plants led to daily intakes of these compounds that exceeded the tolerable daily intakes recommended by the World Health Organization (Hu et al., 2013b). Because of the long-range transport of POPs and their potential risks to the environment and human health, environmental contamination with POPs is a global issue (Brzuzy and Hites, 1996; Hites et al., 2004). Many international treaties, including the Stockholm Convention on POPs, have been signed to control POP emissions and reduce environmental contamination (Lerche et al., 2002; Fiedler, 2007). Reducing emissions of POPs to below the limits defined by these treaties or in national emission control standards is obligatory for some industrial activities.

Development and application of techniques for controlling emissions of POPs can be a technical and economic burden for the involved industries (Liu and Zheng, 2013). Consequently, in developing countries with large industrial sectors, development of sustainable techniques is of importance. The issue of maintaining industrial production while simultaneously controlling and reducing emissions of POPs is an emergent scientific issue in environmental research. Solutions to this problem are dependent on scientific developments in the techniques for inhibition and reduction of POPs. For both industrial development and environmental protection to occur, there are still some important aspects that need to be taken in future research.

In this paper, three important aspects towards sustainable industrial development are discussed. These aspects include: 1) the establishment of a comprehensive system for evaluating the risk from emissions of multiple POPs; 2) determination of indicators for total emissions from multiple POPs; and 3) development of techniques for multi-pollutant control. The relationships among these aspects are shown in Fig. 2. The establishment of a comprehensive system for evaluating the risk from emissions of multiple POPs is essential for determining indicators of total emissions of multiple POPs. The determination of indicators is important to reduce the number of POPs, and therefore cost and time required, for routine monitoring and management of emissions of multiple POPs. The establishment of a comprehensive evaluation system and the determination of indicators are needed to evaluate the efficiency of techniques for reducing emissions of multiple POPs.

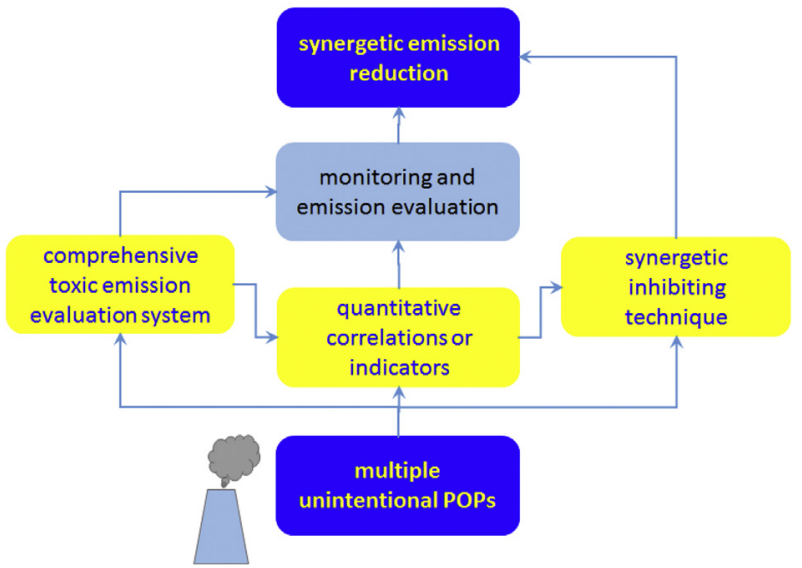

Fig. 2. The relationship about the three aspects associated with synergetic emission reductions.<smiles>Clc1ccc2c(c1)Oc1ccccc1O2</smiles><smiles>Brc1ccc2c(c1)Oc1ccccc1O2</smiles>

PBDDs<smiles>Clc1ccc2ccccc2c1</smiles>
PCNs<smiles></smiles>

halogenated pyrene<smiles>Clc1ccc2c(c1)oc1c(Cl)cccc12</smiles>

$\mathrm{PCDFs}$<smiles>Brc1ccc2c(c1)oc1c(Br)cccc12</smiles>

PBDFs<smiles>Clc1cc(Cl)c(Cl)c(Cl)c1Cl</smiles>

$\mathrm{PeCBz}$

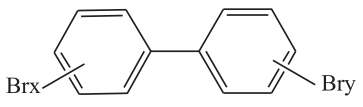

PBBs

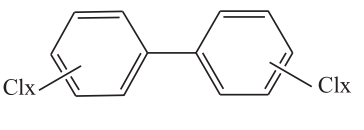

PCBs<smiles>[X]c1ccc2cc3ccccc3cc2c1</smiles>

halogenated anthracene

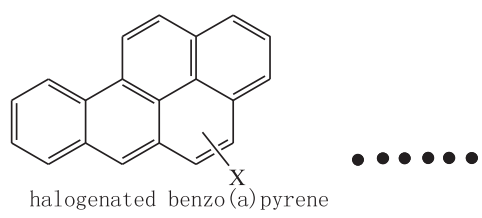

halogenated

halogenated benzo(a) pyrene<smiles>[X]c1ccc2c3c(cccc13)-c1ccccc1-2</smiles>

Fig. 1. Structures of several identified unintentional POPs in industrial emissions. 


\section{Establishment of a comprehensive system for evaluating the emissions of multiple POPs}

There are many different classes of POPs that can be unintentionally produced and emitted during industrial thermal-related processes. The emission levels of these POPs can vary over orders of magnitude. Because of the large range of variables, a system needs to be developed for comprehensive evaluation of the risks to the environment, biota and human health from emissions of multiple POPs. Such an evaluation will be important for determining indicator POPs for the risks from the total emissions from multiple POPs. It will also be essential for assessing the efficiency of reduction techniques on emission of multiple unintentionally produced POPs. To achieve this, the issue of evaluating the overall toxicity from emissions of multiple POPs from different classes and at different concentrations needs to be resolved.

The toxic equivalency factor (TEF) concept was developed to evaluate the overall toxicity from seventeen 2,3,7,8-PCDD/F congeners. The TEFs of these seventeen 2,3,7,8-PCDD/F congeners are determined relative to 2,3,7,8-tetrachlorodibenzo-p-dioxin, which is assigned a TEF of 1 (Van den Berg et al., 2006). The overall toxicity from emissions of the seventeen $2,3,7,8-\mathrm{PCDD} / \mathrm{F}$ congeners can be calculated using Eq. (1). The TEF concept has been extended to several other POPs, including PCBs, PCNs and HxCBz (Van Birgelen, 1998; Blankenship et al., 2000; Villeneuve et al., 2000; Van den Berg et al., 2006). Some studies have even evaluated TEFs for emerging POPs such as PBDDs, PBDFs, PXDD/Fs, Cl-PAHs, Br-PAHs, and PCNs as shown in Fig. 3 (Behnisch et al., 2003; Birnbaum et al., 2003; Van den Berg et al., 2006; Ohura et al., 2007; Horii et al.,
2009; Falandysz et al., 2013; Van den Berg et al., 2013; Falandysz et al., 2014). Although the toxic effect of multiple POPs on human health and biota can not be determined by summing the toxic equivalents (TEQs) of the multiple POPs, the establishment of relative TEFs for multiple POPs could provide a preliminary unified index for evaluating the efficiency of reduction techniques for emissions of multiple POPs from industrial activities. Therefore, studies to determine the TEFs of multiple POPs are important for achieving multi-POP control.

$\mathrm{TEQ}=\sum_{i=1}^{n}$ Concentration $_{(\mathrm{i})} \times \mathrm{TEF}_{(\mathrm{i})}$

\section{Determination of indicator POPs for the total emissions of multiple POPs}

There are many POPs that have be identified in industrial emissions. With regards to some POPs, such as PCDD/Fs, PCBs, PCNs and so on, the costs of sample collection using auto isokinetic sampling technique and instrumental analysis by isotopic dilution high resolution gas chromatography combined with high resolution mass spectrometry (HRGC/HRMS) are very high (Behnisch et al., 2001; Liu and Zheng, 2013). Likewise, the costs of method development and routine monitoring for other POPs are also substantial. Consequently, monitoring the emissions of all POPs would be a huge financial burden. Quantitative relationships or predictive models among multiple POPs could allow for prediction of the overall risks of emissions of multiple POPs based on the data from an individual
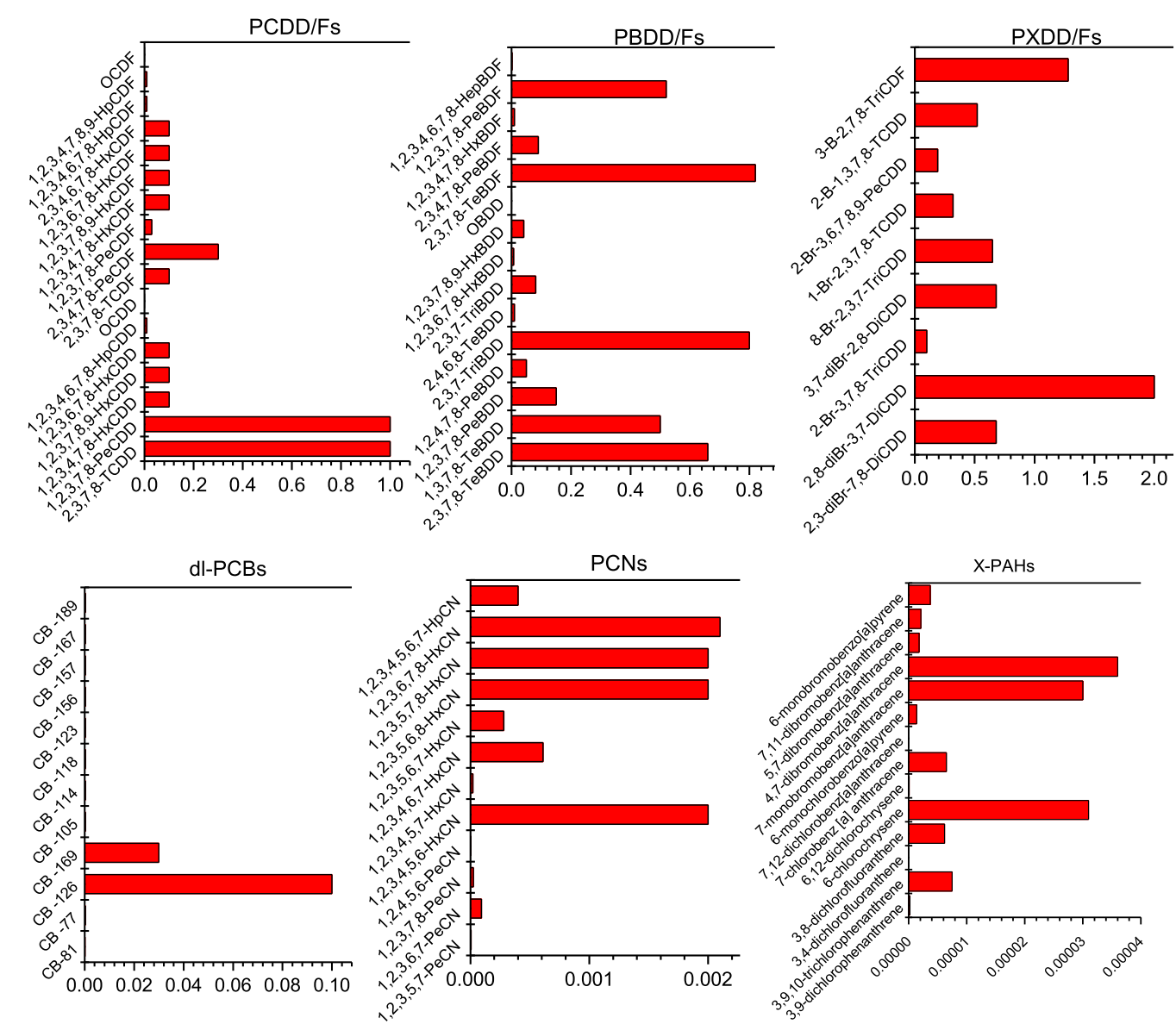

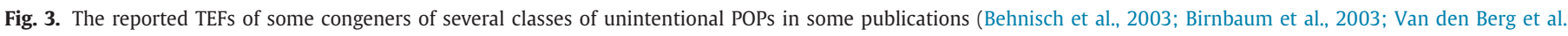
2006; Horii et al., 2009; Falandysz et al., 2013). 


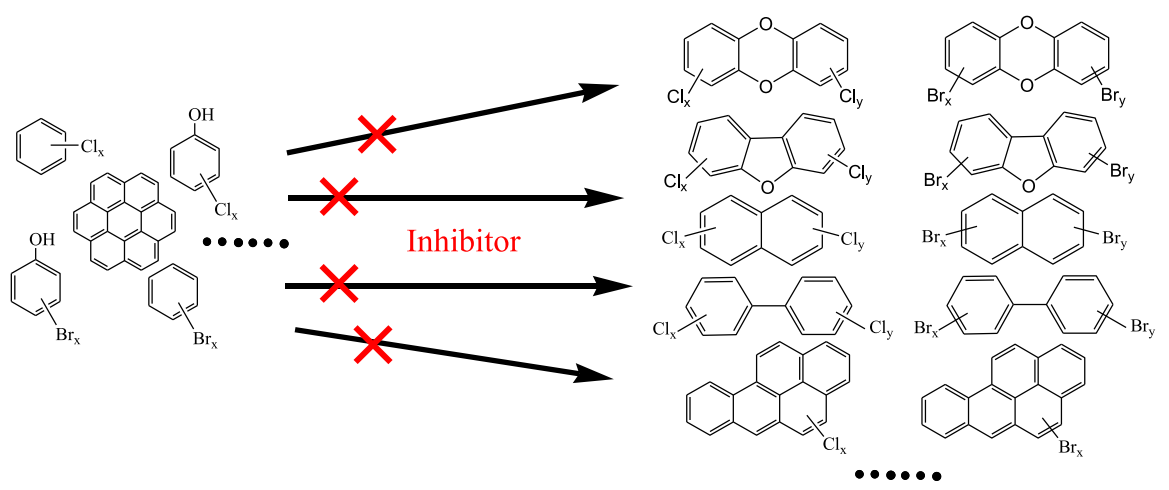

Fig. 4. The schematic of inhibiting the formations of unintentional POPs by blocking the pathway of specific precursors.

POP as an indicator. Therefore, quantitative relationships and a predictive model need to be developed. Quantitative correlations have been reported for several specific POPs that are produced during specific industrial processes, including waste incineration. These include correlations between PCDD/Fs and $\mathrm{HxCBz}$, and PCDD/Fs and PCNs (Oberg and Bergstrom, 1985; Imagawa and Lee, 2001; Liu and Zheng, 2013). Because of the complexity of thermodynamic conditions and the compositions of exhaust gases, it is difficult to determine potential indicators of multiple POPs from industrial thermal sources. To date, a comprehensive investigation of the quantitative correlations among multiple POPs has not been conducted, and appropriate POP indicators have not been determined. Therefore, extensive field investigations with large sample sizes are required for all the industrial sources of POPs.

From the point of view of cost-benefit analysis, determination of indicators that can represent or predict the total emissions of all POPs will be beneficial for monitoring and evaluating industrial activities. Some studies have been performed to determine indicators for specific classes of POPs, such as dioxins, PCBs and PCNs (Fiedler et al., 2000; Liu et al., 2013). For example, Fiedler et al. applied statistical analysis to 109 stack gas samples from waste incineration and metal smelting, and suggested 2,3,4,7,8pentachlorodibenzofuran would be a good indicator for the PCDD/F TEQ (Fiedler et al., 2000). Liu et al. (2013) suggested that CB-118 could be used as an indicator for the PCB TEQ or total concentrations (Liu et al., 2013). Several PCN congeners, including CN50, CN66/67, CN64/68, and CN71/72, have been suggested as indicators for the PCN TEQ (Liu et al., 2015). However, current knowledge about POP indicators is not sufficient for successful practical application of indicator monitoring to multi-POP control in industry. Therefore, extensive studies of the various industrial sources are required to determine potential indicators for total TEQs of multiple POPs, and to clarify the quantitative correlations between these indicators and the total emissions.

\section{Development of techniques for reducing emissions of multiple pollutants}

For some priority POPs, such as dioxins, techniques for inhibiting formation and emission have been developed for specific industrial activities, including metal smelting and waste incineration. Furthermore, guidelines on best available technology and best environmental practices for controlling several specific unintentionally produced POPs, including dioxins, in the industrial sector have been drafted under the Stockholm Convention (UNEP, 2006). However, increasing numbers of POPs are being identified in industrial emissions and entered into international and national treaties, which means their emissions must also be controlled and monitored. If the level of each of these POPs is to be reduced individually, this would be a large time and cost burden for the involved industry. Therefore, techniques for the reduction of multiple pollutants need to be developed to reduce this burden.

Improving the process techniques, mediating the key parameters and spraying inhibitors are the normally adopted methods for reducing the unintentional formation and emission of POPs during industrial thermal processes (Tuppurainen et al., 1998; McKay, 2002). To date, studies have mainly focused on specific POPs, such as PCDD/Fs and dioxin-like PCBs, and specific industrial activities, including waste incineration and metallurgical processes (e.g., iron ore sintering) (McKay, 2002; Aries et al., 2006). Many case studies of the control and reduction of specific POPs, including PCDD/PCDFs and PCBs, from specific industrial processes have been reported (Xhrouet et al., 2002; Pandelova et al., 2005). Brominated flame retardants (BFRs) have been confirmed to be important precursors of brominated dioxins (Weber and Kuch, 2003). However, few studies have reported techniques for reduction of brominated dioxin analogues in emissions from industrial thermal sources. We previously confirmed that impurity in raw materials (e.g., polyvinyl chloride and BFRs) are important in determining PCDD/F and PCB emission levels from secondary nonferrous smelting sources $\mathrm{Hu}$ et al., 2013a). A recent study also found that raw materials influence the emission levels of PCNs and brominated dioxins. Therefore, raw materials should be processed to reduce the contents of POP precursors (e.g., PVC and BFRs) before use in secondary nonferrous smelting, and this might reduce the unintentional production and emission of multiple POPs, such as PCDD/PCDFs, PCBs, PCNs and PBDD/PBDFs. Further studies on reducing emissions of multiple POPs from various industrial sources are required.

Some inhibitors have been prepared for specific POPs, such as PCBs, PBDEs, PCNs and HxCBz. However, an inhibitor that can inhibit formation of multiple POPs at the same time is still needed (Fig. 4). The preparation of functional materials for inhibiting the formation of multiple POPs is an important step to achieve multiPOP control.

\section{Concluding remarks and future perspectives}

Because an increasing number of unintentionally formed POPs are being identified in the emissions from many industrial activities, multi-POP control is of interest. If control of each POP is approached individually, this could lead to a high technical and economic burden for the involved industry. Therefore, from the point of view of cost-benefit analysis, multi-POPs control is a better strategy for sustainable industrial development. However, there are still some challenges to overcome before this can be achieved. Important aspects in future research include the development of a comprehensive system for evaluation of the risks from emissions of multiple POPs, determination of indicator POPs for the emissions of multiple POP, and development of techniques for inhibiting the formation of multiple POPs at the same time. These aspects need 
to be investigated with extensive field studies in all the industries where POP emission is of concern. Considering the wide ranges in physical, chemical, and toxicological properties of the various POPs, the multiple types of industries they can originate from, and variation in the possible analytical methods and their capacities for analysis of multiple POPs, much research needs to be conducted and we are a long way from achieving multi-POP control.

\section{Acknowledgements}

We gratefully acknowledge support from the National 973 program (Grant No. 2015CB453100), the National Natural Science Foundation of China (Grant No. 21477147), and the Strategic Priority Research Program of the Chinese Academy of Sciences (Grant No. XDB14020102).

\section{References}

Akimoto, Y., Aoki, T., Nito, S., Inouye, Y., 1997. Oxygenated polycyclic aromatic hydrocarbons from MSW incinerator fly ash. Chemosphere 34, 263-273.

Aries, E., Anderson, D.R., Fisher, R., Fray, T.A.T., Hemfrey, D., 2006. PCDD/F and "dioxin-like" PCB emissions from iron ore sintering plants in the UK. Chemosphere 65, 1470-1480.

Behnisch, P.A., Hosoe, K., Sakai, S., 2001. Bioanalytical screening methods for dioxins and dioxin-like compounds - a review of bioassay/biomarker technology. Environ. Int. 27, 413-439.

Behnisch, P.A., Hosoe, K., Sakai, S., 2003. Brominated dioxin-like compounds: in vitro assessment in comparison to classical dioxin-like compounds and other polyaromatic compounds. Environ. Int. 29, 861-877.

Birnbaum, L.S., Staskal, D.F., Diliberto, J.J., 2003. Health effects of polybrominated dibenzo-p-dioxins (PBDDs) and dibenzofurans (PBDFs). Environ. Int. 29, 855860 .

Blankenship, A.L., Kannan, K., Villalobos, S.A., Villeneuve, D.L., Falandysz, J., Imagawa, T., Jakobsson, E., Giesy, J.P., 2000. Relative potencies of individual polychlorinated naphthalenes and halowax mixtures to induce Ah receptormediated responses. Environ. Sci. Technol. 34, 3153-3158.

Brzuzy, L.P., Hites, R.A., 1996. Global mass balance for polychlorinated dibenzo-pdioxins and dibenzofurans. Environ. Sci. Technol. 30, 1797-1804.

Buser, H.R., Dolezal, I.S., Wolfensberger, M., Rappe, C., 1991. Polychlorodibenzothiophenes, the sulfur analogs of the polychlorodibenzofurans identified in incineration samples. Environ. Sci. Technol. 25, 1637-1643.

Du, B., Zheng, M.H., Huang, Y.R., Liu, A.M., Tian, H.H., Li, L.L., Li, N., Ba, T., Li, Y.W., Dong, S.P., Liu, W.B., Su, G.J., 2010. Mixed polybrominated/chlorinated dibenzop-dioxins and dibenzofurans in stack gas emissions from industrial thermal processes. Environ. Sci. Technol. 44, 5818-5823.

Falandysz, J., Fernandes, A., Gregoraszczuk, E.M.R., 2013. Aryl hydrocarbon receptor mediated (dioxin-like) relative potency factors for chlornaphthalenes. Organohalogen Compd. 75, 336-338.

Falandysz, J., Fernandes, A., Gregoraszczuk, E., Rose, M., 2014. The toxicological effects of halogenated naphthalenes: a review of aryl hydrocarbon receptormediated (Dioxin-like) relative potency factors. J. Environ. Sci. Health Part C 32, 239-272.

Fiedler, H., 2007. National PCDD/PCDF release inventories under the Stockholm convention on persistent organic pollutants. Chemosphere 67, S96-S108.

Fiedler, H., Lau, C., Eduljee, G., 2000. Statistical analysis of patterns of PCDDs and PCDFs in stack emission samples and identification of a marker congener. Waste Manag. Res. 18, 283-292.

Hites, R.A., Foran, J.A., Carpenter, D.O., Hamilton, M.C., Knuth, B.A., Schwager, S.J., 2004. Global assessment of organic contaminants in farmed salmon. Science 303, 226-229.

Horii, Y., Khim, J.S., Higley, E.B., Giesy, J.P., Ohura, T., Kannan, K., 2009. Relative potencies of individual chlorinated and brominated polycyclic aromatic hydrocarbons for induction of aryl hydrocarbon receptor-mediated responses. Environ. Sci. Technol. 43, 2159-2165.

Horii, Y., Ok, G., Ohura, T., Kannan, K., 2008. Occurrence and profiles of chlorinated and brominated polycyclic aromatic hydrocarbons in waste incinerators. Environ. Sci. Technol. 42, 1904-1909.

Hu, J., Zheng, M., Nie, Z., Liu, W., Liu, G., Zhang, B., Xiao, K., 2013a. Polychlorinated dibenzo-p-dioxin and dibenzofuran and polychlorinated biphenyl emissions from different smelting stages in secondary copper metallurgy. Chemosphere 90, 89-94.

Hu, J.C., Zheng, M.H, Liu, W.B. Li, C.L, Nie, Z.Q, Liu, G.R., Xiao, K. Dong S.J., 2013b. Occupational exposure to polychlorinated dibenzo-p-dioxins and dibenzofurans, dioxin-like polychlorinated biphenyls, and polychlorinated naphthalenes in workplaces of secondary nonferrous metallurgical facilities in China. Environ. Sci. Technol. 47, 7773-7779.
Imagawa, T., Lee, C.W., 2001. Correlation of polychlorinated naphthalenes with polychlorinated dibenzofurans formed from waste incineration. Chemosphere 44 $1511-1520$.

Lerche, D., Van de Plassche, E., Schwegler, A., Balk, F., 2002. Selecting chemical substances for the UN-ECE POP protocol. Chemosphere 47, 617-630.

Liu, G., Cai, Z., Zheng, M., Jiang, X., Nie, Z., Wang, M., 2015. Identification of indicator congeners and evaluation of emission pattern of polychlorinated naphthalenes in industrial stack gas emissions by statistical analyses. Chemosphere 118, 194 200.

Liu, G.R., Zheng, M.H., 2013. Perspective on the inclusion of polychlorinated naphthalenes as a candidate POP in Annex C of the Stockholm Convention. Environ. Sci. Technol. 47, 8093-8094.

Liu, G.R., Zheng, M.H., Cai, M.W., Nie, Z.Q., Zhang, B., Liu, W.B., Du, B., Dong, S.J. Hu, J.C., Xiao, K., 2013. Atmospheric emission of polychlorinated biphenyls from multiple industrial thermal processes. Chemosphere 90, 2453-2460.

Liu, G.R., Zheng, M.H., Liu, W.B., Wang, C.Z., Zhang, B., Gao, L.R., Su, G.J., Xiao, K. Lv, P., 2009. Atmospheric emission of PCDD/Fs, PCBs, hexachlorobenzene, and pentachlorobenzene from the coking industry. Environ. Sci. Technol. 43, 91969201.

Liu, G.R., Zheng, M.H., Lv, P., Liu, W.B., Wang, C.Z., Zhang, B., Xiao, K., 2010. Estimation and characterization of polychlorinated naphthalene emission from coking industries. Environ. Sci. Technol. 44, 8156-8161.

Lv, P., Zheng, M.H., Liu, G.R., Liu, W.B., Xiao, K., 2011. Estimation and characterization of PCDD/Fs and dioxin-like PCBs from Chinese iron foundries. Chemosphere 82, 759-763.

Ma, J., Addink, R., Yun, S.H., Cheng, J.P., Wang, W.H., Kannan, K., 2009. Polybrominated dibenzo-p-dioxins/dibenzofurans and polybrominated diphenyl ethers in soil, vegetation, workshop-floor dust, and electronic shredder residue from an electronic waste recycling facility and in soils from a chemical industrial complex in Eastern China. Environ. Sci. Technol. 43, 7350-7356.

McKay, G., 2002. Dioxin characterisation, formation and minimisation during municipal solid waste (MSW) incineration: review. Chem. Eng. J. 86, 343-368.

Oberg, T., Bergstrom, J.G.T., 1985. Hexachlorobenzene as an indicator of dioxin production from combustion. Chemosphere 14, 1081-1086.

Ohura, T., Morita, M., Makino, M., Amagai, T., Shimoi, K., 2007. Aryl hydrocarbon receptor-mediated effects of chlorinated polycyclic aromatic hydrocarbons. Chem. Res. Toxicol. 20, 1237-1241.

Pandelova, M.E., Lenoir, D., Kettrup, A., Schramm, K.W., 2005. Primary measures for reduction of PCDD/F in co-combustion of lignite coal and waste: effect of various inhibitors. Environ. Sci. Technol. 39, 3345-3350.

Shih, T.S., Chen, H.L., Wu, Y.L., Lin, Y.C., Lee, C.C., 2006. Exposure assessment of polychlorinated dibenzo-p-dioxins and dibenzofurans (PCDD/Fs) in temporary municipal-waste-incinerator maintenance workers before and after annual maintenance. Chemosphere 64, 1444-1449.

Shih, T.S., Lee, W.J., Shih, M., Chen, Y.C., Huang, S.L., Wang L.C. Chang-Chieng, G.P. Tsai, P.J., 2008. Exposure and health-risk assessment of polychlorinated dibenzop-dioxins and dibenzofurans (PCDD/Fs) for sinter plant workers. Environ. Int. 34 102-107.

Tuppurainen, K., Halonen, I., Ruokojarvi, P., Tarhanen, J., Ruuskanen, J., 1998. Formation of PCDDs and PCDFs in municipal waste incineration and its inhibition mechanisms: a review. Chemosphere 36, 1493-1511.

UNEP, 2006. Stockholm Convention on Persistent organic Pollutants http: //chm.pops.int/Implementation/BATandBEP/Guidance/tabid/3636/Default.aspx. (accessed 9.10.14.).

Van Birgelen, A.P.J.M., 1998. Hexachlorobenzene as a possible major contributor to the dioxin activity of human milk. Environ. Health Perspect. 106, 683-688.

Van den Berg, M., Birnbaum, L.S., Denison, M., De Vito, M., Farland, W., Feeley, M., Fiedler, H., Hakansson, H., Hanberg, A., Haws, L., Rose, M., Safe, S., Schrenk, D. Tohyama, C., Tritscher, A., Tuomisto, J., Tysklind, M., Walker, N., Peterson, R.E., 2006. The 2005 World Health Organization reevaluation of human and mammalian toxic equivalency factors for dioxins and dioxin-like compounds. Toxicol. Sci. 93, 223-241.

Van den Berg, M., Denison, M.S., Birnbaum, L.S., DeVito, M.J., Fiedler, H., Falandysz, J., Rose, M., Schrenk, D., Safe, S., Tohyama, C., Tritscher, A., Tysklind, M., Peterson, R.E., 2013. Polybrominated dibenzo-p-dioxins, dibenzofurans, and biphenyls: inclusion in the toxicity equivalency factor concept for dioxin-like compounds. Toxicol. Sci. 133, 197-208.

Villeneuve, D.L., Kannan, K., Khim, J.S., Falandysz, J., Nikiforov, V.A. Blankenship, A.L., Giesy, J.P., 2000. Relative potencies of individual polychlorinated naphthalenes to induce dioxin-like responses in fish and mammalian in vitro bioassays. Arch. Environ. Contam. Toxicol. 39, 273-281.

Wagrowski, D.M., Hites, R.A., 2000. Insights into the global distribution of polychlorinated dibenzo-p-dioxins and dibenzofurans. Environ. Sci. Technol. 34, 29522958

Weber, R., Kuch, B., 2003. Relevance of BFRs and thermal conditions on the formation pathways of brominated and brominated-chlorinated dibenzodioxins and dibenzofurans. Environ. Int. 29, 699-710.

Xhrouet, C., Nadin, C., De Pauw, E., 2002. Amines compounds as inhibitors of PCDD/Fs de novo formation on sintering process fly ash. Environ. Sci. Technol. 36, 2760-2765.

Yang, H.H., Lee, W.J., Chen, S.J., Lai, S.O., 1998. PAH emission from various industrial stacks. J. Hazard. Mater. 60, 159-174.

Zhang, X.L., Tao, S., Liu, W.X., Yang, Y., Zuo, Q., Liu, S.Z., 2005. Source diagnostics of polycyclic aromatic hydrocarbons based on species ratios: a multimedia approach. Environ. Sci. Technol. 39, 9109-9114. 